\title{
Analysis on Quantified Self-Behavior of Customers in Food Consumption under the Perspective of Social Networks
}

\author{
Lei Lei $\mathbb{D}^{1,2}$ Yaling $\mathrm{Zhu}^{3}$ and Qiang Liu $\mathbb{D}^{4}$ \\ ${ }^{1}$ School of Economics and Finance, Xi'an Jiaotong University, Xi'an710064, China \\ ${ }^{2}$ Sports Department, Northwest A\&F University, Yangling 712100, China \\ ${ }^{3}$ International Business School, Shaanxi Normal University, Xi'an 710119, China \\ ${ }^{4}$ Sports Department, Central South University, Changsha 410083, China \\ Correspondence should be addressed to Qiang Liu; answerxiaoliu@163.com
}

Received 19 May 2021; Revised 23 August 2021; Accepted 9 September 2021; Published 6 October 2021

Academic Editor: Fei Xiong

Copyright $\odot 2021$ Lei Lei et al. This is an open access article distributed under the Creative Commons Attribution License, which permits unrestricted use, distribution, and reproduction in any medium, provided the original work is properly cited.

\begin{abstract}
China is still facing the double challenges of over nutrition and malnutrition. One of the main reasons is the lack of residents' understanding of the nutritional value of food. Quantified self, as a measure of consumer self-activity, has been used to analyze food consumption behavior recently. Although the research results are increasing, the conclusions are not consistent. What's more, previous literatures did not consider food consumption behavior based on the theory of information perception and the risk perception theory. In addition to obtaining information through their own human capital for quantitative activities, consumers will also obtain information through social networks. In view of the above understanding, this study uses experimental design and field survey to obtain data, uses Heckman two-step method and PLS path modeling method to analyze the impact of consumers' quantified self-behavior on their health food consumption, and discusses the moderating role of social networks based on the perspective of complex network. The results show that (1) consumers' health awareness can promote their choice of quantified self-behavior, (2) consumers' quantified self-behavior is helpful to promote their purchase intention and purchase scale of healthy food, and (3) social networks play a positive moderating role in consumers' quantified self-influence on their healthy food consumption. Both emotional networks and instrumental networks have significant moderating effect, but the formal is stronger. This article not only considers the relationship between food consumption behavior and social network but also the enhances literature based on the theory of information perception and the risk perception theory.
\end{abstract}

\section{Introduction}

A state relies on people and people relies on food. With the improvement of living standards and the growth of residents' income, the total dietary intake of residents in China has shown a gradual improvement trend in the past decade. From the data of Research Group of China's Health and Nutrition (2019), the malnutrition rate of residents aged 18 years and above as well as that of children younger than five years have decreased from $8 \%$ to $22.16 \%$ in 2000 to $2.2 \%$ and $9.3 \%$ in 2019 , respectively. However, at the same time, the dietary intake structure of residents is unbalanced, such as excessive consumption of livestock meat and fat, low consumption of cereal food, and general lack of vitamins [1].
One of the main reasons for the coexistence of malnutrition and over nutrition is that the residents are lacking the understanding of the nutritional value of food and the rational judgment of nutrition. During the epidemic of COVID-19 in 2020, residents' consumption behavior also reflected the same problem. On one hand, the residents bought the food not according to their needs but to panic buying and hoarding. On the other hand, the residents concentrated on purchasing food like rice, flour, oil, meat, and so on, although the willingness to buy dairy products, coarse grains, and frozen vegetables was not high [2]. Therefore, the key problem to be solved in practice is to make the residents realize the nutritional value of food, to form the concept of healthy nutrition, to optimize the food 
consumption structure, and improve the status of malnutrition and over nutrition of Chinese residents.

Quantified self as a consumer tracking measure of selfactivity $[3,4]$ and the process of forming self-knowledge and conventional habits based on it, brings about the change in consumers' behavior. Recently, quantified self is also used in the research of analyzing food consumption behavior of consumers [4]. Although the results of quantified self-analysis in residents' consumption behavior are increasing day by day, the conclusion shows a dilemma of quantified self in consumption, which was like chicken ribs. According to the theory of information perception, quantification is the way to transform the professional and theoretical food safety assessment information into the data information that consumers can understand [5]. Consumers choose the appropriate food according to the food composition, safety level, and other information. This kind of quantified self-behavior is a short-term choice behavior made by consumers based on the food information provided by producers; it has little effect on consumers' food nutrition concept and health behavior [6, 7]. According to the risk perception theory, consumers will improve the collection, management, and reflection of quantitative information of self-health and demand status (such as blood pressure and blood glucose level) under risk perception and then accurately intervene and control self-behavior decision-making [4]. This quantified self-behavior is to select appropriate food according to consumers' health status; it has a positive role in promoting the formation of nutrition concept and health behavior of consumers [8,9]. In addition, many scholars also point out that consumers' quantified selfbehavior has the problem of short-term participation. Different conclusions make it necessary to further study the quantified self in food consumption: is the quantified self in food consumption effective for residents' health? Is quantified self-behavior a "chicken rib" to the formation of residents' nutrition concept? These problems need further analysis and verification in theory.

In the implementation process of quantified self-behavior, consumers obtain information not only through their own human capital but also through social networks for quantitative activities. If consumers want to eat safe and nutritious food, firstly, they need to obtain information about food quality, safety, and ingredients. Due to the limitation of cost and the profit-making purpose of food manufacturers, food manufacturers may adopt opportunistic behavior in the disclosure of information on food quality, safety, and nutrition [10]. At this time, consumers can only obtain the related information through their own efforts. To obtain more information about food quality, consumers will pay a high cost for searching information if they only make efforts to obtain it by themselves. At this time, social networks provide opportunities for consumers. The so-called social network refers to "a relatively stable association system formed between social individuals because of interaction." In this system, network members can exchange, interact, and share information. Through social networks, those consumers who have less information can establish effective contact with those who have more information. Consumers who have less information will get the information they need from consumers who have more information, which makes food information shared between two kinds of consumers and reduces a lot of information searching costs [11]. Meanwhile, the mutual sharing of network members could help to promote consumers' quantitative behavior, so as to improve consumers' concept for food safety and nutrition.

Based on the complex social network theory, this study analyzes the impact of consumers' quantified self-behavior on their healthy food consumption and explores the role of social networks. The main contents include the following: firstly, whether or not to quantify self in residents' daily food consumption; secondly, what is the impact of quantified selfbehavior on residents' health food consumption intention and scale; thirdly, whether social network has a moderating effect in the process of quantified self-behavior on residents' health food consumption. The article is divided into following parts: Section 2 is theoretical analysis and hypothesis, which theoretically analyses the relationship between quantified self and food consumption based on social network. Section 3 is materials and methods, which introduces the data sources and main methods. Section 4 is results and discussion, which shows the main empirical results and discusses them. The final part is conclusion, which summarizes the full and puts forward the shortcomings of the article.

\section{Theoretical Analysis and Hypothesis}

2.1. Quantified Self-Behavior of Healthy Food Consumers. With the improvement of people's living standards, food consumption of residents has gradually changed from "full" to "healthy." In recent years, food poisoning, overdue resale, and other problems have further strengthened consumers' preference for healthy food. Compared with consumers who buy ordinary food, those who prefer healthy food are more likely to pay attention to the origin, composition, and nutritional structure of food, and these information often need to be screened and compared. Relevant theories point out that in order to accurately predict the extent of food safety risks to their own health, consumers should understand the sources of risk variability and risk magnitude, acquire self-knowledge through quantitative information, and scientifically assess food safety risks through the levels of harmful and nutritional components. It is necessary and important to develop a suitable diet to ensure the safety and quality of individualized food [12]. Therefore, we propose Hypothesis 1.

Hypothesis 1. Compared with other consumers, consumers with healthy food attitude are more willing to take quantified self-behavior.

\subsection{Influence of Quantified Self-Behavior on Healthy Food} Consumption. The application of quantified self in food consumption is mainly reflected in two aspects: first, the residents' attention to food quantitative data information will improve their sensitivity and alertness to the 
information of food harmful ingredients and their harmful amount, so as to enhance the accurate identification of food safety, risk, and efficiency $[8,12]$. The preference for quantitative information will arouse consumers' quantitative consumption intention, that is, through tracking and observing self-related data (such as their maximum tolerance of specific food additives and daily consumption) and product efficiency data (such as the content of specific food additives and the magnitude of possible harm to the body), the self-behavior state and product efficiency knowledge will be formed. Based on this, the consumption decision is optimized [13].

Secondly, under the health risk perception, residents will improve the collection, management, and reflection of quantitative information of self-health and demand status (such as blood pressure and blood glucose level), so as to accurately intervene and control self-behavior decisionmaking [4]. Under the residents' own health perception, the residents' food consumption decisions will show a precise preference, which not only pay more attention to the quantitative data information of food but also purchase food according to the quantitative information of their own needs and make food decisions accurately and rationally based on objective quantitative data rather than subjective assumptions [14]. Quantitative information will enable residents to rethink their eating habits in a way driven by data rather than experience, so as to rationally decide food purchase and scientifically plan food intake. Quantified self will identify residents' self-health level and personality needs, further more intuitively understand self-status [15], judges product effectiveness based on quantitative data information, establish the association between product data indicators and consumers themselves, and realize accurate and rational consumption decision [16]. Therefore, we propose $\mathrm{Hy}-$ potheses 2 and 3.

Hypothesis 2. Quantified self-behavior is helpful to strengthen consumers' willingness to buy healthy food.

Hypothesis 3. Quantified self-behavior is helpful to increase purchasing amount of healthy food consumption.

\subsection{The Effect of Social Networks on Quantified Self-Behavior} and Healthy Food Consumption. Consumers' searching cost is high because they usually rely on themselves to collect information about food safety, nutrition, and so on. Social networks provide consumers with information channels [17]. In social networks, information sharing behavior is a common behavior, which network members share information accidentally found or needed by others [18]. Information sharing behavior is a very important social behavior, which often occurs in the network or social groups, and is not a special behavior of individual [19]. Instead, it is a process of cooperation among network members under the condition of social networks, in which information providers transfer information to information searchers [20]. Also, social media influencers can shape corporate brand reputation through online followers' trust, value creation, and purchase intentions [21]. In the sharing economy platforms, such as social networks, digital personal reputation and feedback systems facilitate interaction and trust between strangers and further form customer loyalty [22]. This means that the trust formed during the interaction of social networks further produce an effect on the decision of buying [23]. Another aspect, when customers develop a sense of trust in each other in interaction of social networks, consumer cognition will also affect the decision-making behavior. Drugău-Constantin and Mirică pointed out that consumer cognition could be reducible to neurophysiological functioning, and this would influence consumers' choice $[24,25]$.That is to say, social networks provide information channels for members to share information, which is related to individuals' health or food safety. This information further help individuals to improve their quantified self-behavior. On other way, social networks can influence quantified self-behavior through information sharing among members and then affect consumers' healthy food consumption.

Social networks are composed of the relationship between different members. The more the members, the more complex the connection and the more complex the social network. Social networks with different complexity may affect both quantified self-behavior and food consumption behavior. Assuming that the network is only a star-style network with four consumers (Figure 1(a)), the core consumer $S_{1}$ can adopt information sharing strategy after obtaining the information, whether it is quantitative information or food health information, the rest of consumers can get it for free, while they can share the information again or choose not to share it. In Figure 1(b) star network with six consumers, consumers choose the sharing strategy as (a), but because it has more network connections, the speed of information transmission and sharing is wider. In the type of Figure 1(c) network connection, in addition to the core consumers and other consumers, there are also connections between other consumers such as $S_{21}$ and $S_{22}$. In this case, the probability of other consumers choosing information sharing strategy will increase, that is, the multiconnection relationship between different members in the same network will strengthen the information sharing and transmission. In addition, social networks can also be reconnected through members. In the two star networks (a) and (b) of consumers, there are two kinds of connection choices: one is to form a new network structure as Figure 1(d) for the connection between the core consumers of star network (a) and the other consumers of star network (b); the other is to form a new network structure as Figure 1(e) for the increase in connection between the core consumers of star network (a) and the core consumers of star network (b). However, compared with social network (d), social network (e) breaks the original equilibrium and forms a new network because of the connection between core consumers. The network scope is wider, and core consumers will choose information sharing, whereas other consumers may choose not to share information because of free-riding behavior. Thus, the sharing behavior in network (e) is more wide. It means the more complex the social networks are, the stronger the 


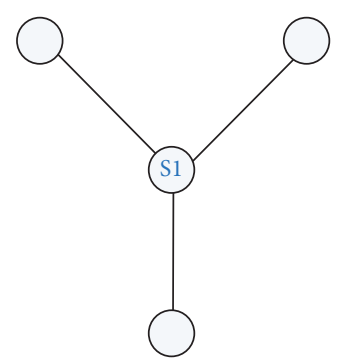

(a)

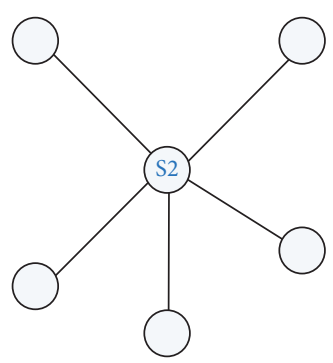

(b)

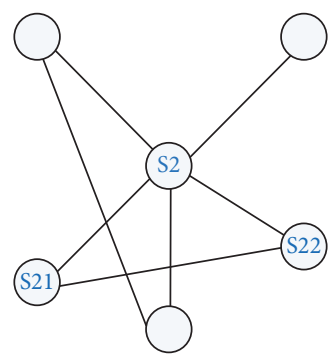

(c)

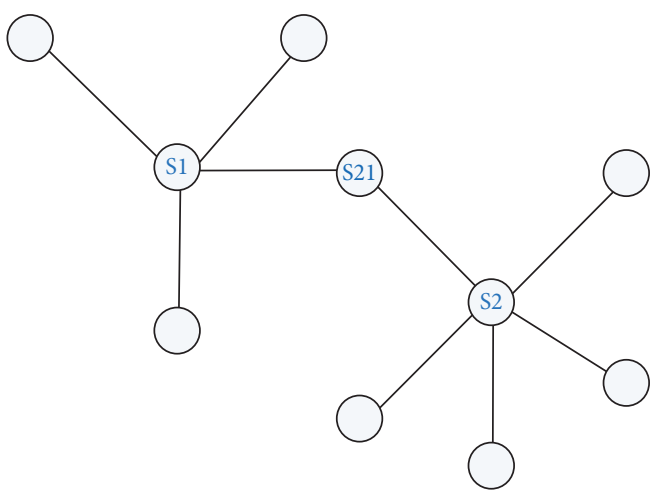

(d)

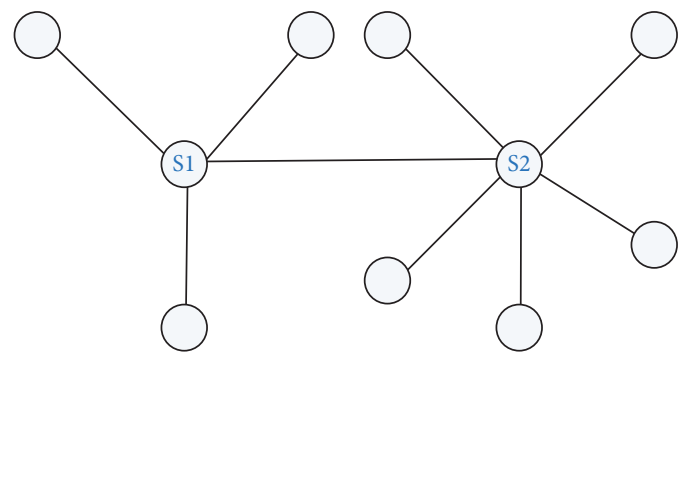

(e)

FIgURE 1: Social networks of different complexity.

impact of quantified self-behavior on consumers' healthy food consumption is. Therefore, we propose Hypothesis 4 .

Hypothesis 4. Social networks will moderate the relationship between quantified self and consumers' healthy food consumption.

With the continuous development of China's social economy and the increase in population flow, the traditional concept of family has been affected. Individuals begin to pay more attention to individual value and interests and change from survival rationality to social rationality [26]. With the change, the coverage and strength of social relationship have changed from mainly emotional network to instrumental network mixed with emotional network. Emotional network is based on family concept and blood relationship, which has strong stability and nonselectivity [26]. Moreover, social network based on emotion and blood relationship pays more attention to individual health than individual achievement. Just like parents are more concerned about their children's health instead of their children's academic and career achievements. The instrumental network is mostly based on the relationship of career or classmates. Network members will establish more externalized social relations according to their own purposes and needs and network connection is mainly based on mutual interests. More attention is paid to individual achievement rather than physical health. For example, instrumental network members are more likely to start a business and share employment experience together rather than focus on health together [27]. In instrumental network, the information shared are more career related than health related. Therefore, we propose Hypothesis 5.

Hypothesis 5. Compared with instrumental network, emotional network has a stronger moderating effect.

\section{Materials and Methods}

\subsection{Subjects and Methods}

3.1.1. Experimental Operation. The purpose of this experiment is to examine the impact of quantified self on residents' willingness and scale of healthy food consumption. The subjects were randomly divided into control group (CQG), active quantitative group (AQG), and passive quantitative group (PQG). The control group did not provide any information. The passive quantitative experimental group was offered food information including protein, carbohydrate, calorie, and so on, and provided the minimum nutrients needed by the human body every day. The food composition information of the active quantitative experimental group was hidden, and the subjects could actively view the food composition information or directly select without viewing it.

90 students from a university in Shaanxi participated in the experiment, and the subjects were arranged to participate in the experiment within a certain period. Before the experiment, the basic statistical characteristics, such as gender, age, food consumption preferences, and habits of the subjects were investigated with a short questionnaire. The subjects were randomly divided into control group (CQG), active quantization group (AQG), and passive quantization 
group (AQG). The demographic characteristics of the whole sample are shown in Figure 2.

From Figure 2, in terms of gender, the distribution of the control group and the experimental group is similar, and the number of male subjects is equal to or more than that of female subjects. In the control group, male and female subjects accounted for $50 \%$, respectively. In the active quantitative group and the passive quantitative group, male subjects accounted for $53.33 \%$ and $63.3 \%$, respectively. In terms of age distribution, the minimum age of the subjects is 17 years, the maximum age is 25 years, and the overall age distribution is relatively uniform. For example, in the control group, $43.3 \%$ of the subjects were younger than 20 years, $36.7 \%$ of the subjects were between 21 and 23 years, and $20 \%$ of the subjects were older than 24 years. It can be seen from Figure 2 that the distribution of gender and age in different groups are similar. Because the samples are randomly assigned to different groups, the results show that the comparison between different groups is reliable.

3.1.2. Investigation Research. Based on the in-depth understanding of the existing research maturity scale and interviews with experts, we developed the related variable measurement scale $w$ combined with the research situation. After the prediction test of 5 scholars in related fields and 30 ordinary consumers, this study finally determined the formal questionnaire. In order to ensure the efficient development of the survey, in addition to using the network questionnaire survey, this study also took some urban and rural residents and college students in Shaanxi Province and Zhejiang Province as the survey subjects. A total of 1000 questionnaires were distributed, and 987 questionnaires were collected. After screening out 45 invalid questionnaires, such as missing answers and consistent selection of test items, 942 valid questionnaires were finally obtained (the effective recovery rate was $94.2 \%$ ). The demographic characteristics of the respondents are shown in Table 1.

\subsection{Variable Selection and Measurement}

3.2.1. Quantified Self. Combined with the research viewpoints of Zhang et al. [6] and Zhou et al [28], 10 items of consumers' quantitative information preference and quantitative willingness to participate in consumption were determined, respectively, including "I am very concerned about food nutrition," "I prefer healthy food," "I am willing to rationally consume food by evaluating food nutrition," "I am willing to participate in food consumption by evaluating food nutrition," "I am willing to choose safe alternative food with the same nutritional efficiency according to the dietary needs after quantified self." In this study, the confirmatory factor analysis of the questionnaire fitted well: $\chi^{2} / \mathrm{df}=3.26$, $\mathrm{RMSEA}=0.06, \mathrm{NFI}=0.998, \mathrm{GFI}=0.999$, and $\mathrm{CFI}=0.999$. Internal consistency coefficient of questionnaire is 0.742 . Analyzing dimension reduction by SPSS, according to the standard of eigenvalue greater than 1 , two variables were obtained: consumer quantitative information preference and quantitative willingness and five items belong to the former and five items belong to the latter. The results are consistent with the expectation of the questionnaire design.

3.2.2. Healthy Food Consumption. Referring to the measurement scale developed by Penning and Wansink, the scale of residents' healthy food consumption is compiled, including 10 items of healthy food consumption willingness and scale, such as "I prefer organic food to ordinary food," "I will pay attention to the nutritional components of food when I buy it," "I will pay attention to whether food contains harmful ingredients such as additives when I buy it," "I will pay attention to the food quality when I buy it," "The amount of pork purchased per week," "the amount of organic pork purchased per week," "the cost of fruit purchased per week," and "the frequency of eating instant noodles and other fast food products per week." In this study, the confirmatory factor analysis of the questionnaire fitted well: $\chi^{2} / \mathrm{df}=2.84$, RMSEA $=0.07, \mathrm{NFI}=0.999, \mathrm{GFI}=0.998$, and $\mathrm{CFI}=0.999$. Internal consistency coefficient of questionnaire is 0.728 . Through factor analysis and dimensionality reduction, two variables were obtained according to the standard of eigenvalue greater than 1: consumer's food consumption intention and food consumption scale, with five items belonging to the former, four items belonging to the latter, and one item was deleted due to low load value. The results were basically consistent with the expectation of the questionnaire design.

3.2.3. Social Networks. The social network questionnaire compiled by Fang [29] adopted 13 items, such as the number of my brothers and sisters, the number of my friends in wechat group, the number of communities I join in on the Internet, and so on.Instrumental network contains 6 items, such as "I keep close contact with many classmates" and the like; emotional network contains 7 items, such as "I have close relationship with relatives of the same age" and the like (Kim and Lee). In this study, the confirmatory factor analysis of the questionnaire fitted well: $\chi^{2} / \mathrm{df}=2.69$, RMSEA $=0.08$, $\mathrm{NFI}=0.999$, GFI $=0.999$, and $\mathrm{CFI}=0.98$. Internal consistency coefficient of questionnaire is 0.676 . According to the criterion of eigenvalue greater than 1 , two variables were obtained: emotional network and instrumental network, with 7 items belonging to the former and 6 items belonging to the latter. The results were consistent with the expectation of the questionnaire design.

\subsection{Empirical Methods and Models}

3.3.1. Heckman Two-Step Method. Heckman two-step method is mainly used to deal with sample bias and selfselection problems, and it can also solve endogenous problems in self-selection behavior. In this article, the residents also have the problems of self-selection and sample bias. To study the influence of quantified self on the willingness and scale of healthy food consumption, the equation of quantified self and scale of food consumption is set as follows: 

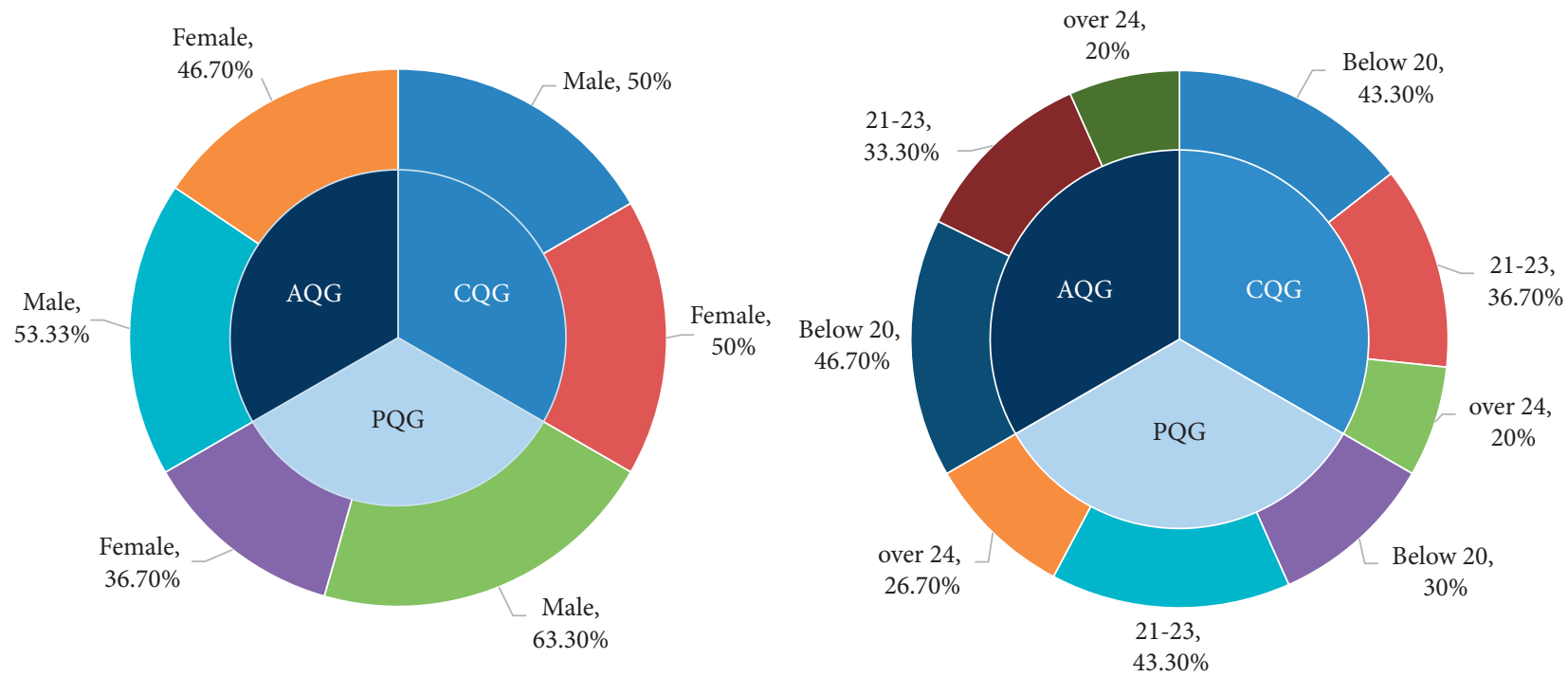

FIGURE 2: Distribution of gender and age in different groups.

TABle 1: Demographic characteristics of respondents.

\begin{tabular}{|c|c|c|c|c|c|c|c|}
\hline \multicolumn{2}{|c|}{ Category } & Number & Percentage & Category & & Number & Percentage \\
\hline \multirow{2}{*}{ Gender } & Male & 469 & 49.79 & \multirow{3}{*}{$\begin{array}{l}\text { Average net monthly } \\
\text { income }\end{array}$} & Below $\$ 300$ & 249 & 26.43 \\
\hline & Female & 473 & 50.21 & & $\$ 300-\$ 800$ & 225 & 23.89 \\
\hline \multirow{4}{*}{ Age } & Below 25 & 43 & 4.56 & & $\$ 800-\$ 1500$ & 334 & 35.46 \\
\hline & $26-35$ & 298 & 31.63 & \multirow{3}{*}{ Residence } & Above $\$ 1500$ & 134 & 14.23 \\
\hline & $36-45$ & 291 & 30.89 & & Urban & 445 & 47.24 \\
\hline & Above 46 & 310 & 32.91 & & Rural & 497 & 52.76 \\
\hline \multirow{2}{*}{ Education } & $\begin{array}{c}\text { Below bachelor } \\
\text { degree }\end{array}$ & 331 & 35.14 & \multirow[b]{2}{*}{ Health awareness } & High & 598 & 63.48 \\
\hline & $\begin{array}{c}\text { Above bachelor } \\
\text { degree }\end{array}$ & 611 & 64.86 & & Medium & 210 & 22.29 \\
\hline \multirow{4}{*}{$\begin{array}{l}\text { Minimum net monthly } \\
\text { income }\end{array}$} & Below $\$ 150$ & 221 & 23.46 & \multirow{4}{*}{ Health knowledge } & Low & 134 & 14.23 \\
\hline & $\$ 150-\$ 300$ & 247 & 26.22 & & High & 250 & 26.54 \\
\hline & $\$ 300-\$ 800$ & 346 & 36.73 & & Medium & 289 & 30.68 \\
\hline & Above $\$ 800$ & 128 & 13.59 & & Low & 403 & 42.78 \\
\hline
\end{tabular}

$$
y_{1 i}=\chi_{1 i} \beta_{1}+\varepsilon_{1 i}
$$

Here, $y_{1 i}$ is scale of healthy food consumption and $x_{1 i}$ is quantified self. The quantified self choice equation was as follows:

$$
y_{2 i}=\chi_{2 i} \beta_{2}+\varepsilon_{2 i}
$$

Here, $y_{2 i}$ is whether to choose quantified self and $x_{2 i}$ is factors influencing self quantification, such as age, gender, education, and so on. If equation (1) is direct estimated, we will get the estimator with selective bias.

It can be seen from the model

$$
\mathrm{E}\left(\varepsilon_{1 i} \mid y_{2 i}^{*} \geq 0\right)=\mathrm{E}\left(\varepsilon_{1 i} \mid \varepsilon_{2 i} \geq-\chi_{2 i} \beta_{2}\right)
$$

and

$$
\mathrm{E}\left(y_{1 i} \mid \chi_{1 i}, y_{2 i}^{*} \geq 0\right)=\chi_{1 i} \beta_{1}+\mathrm{E}\left(\varepsilon_{1 i} \mid \varepsilon_{2 i} \geq-\chi_{2 i} \beta_{2}\right)
$$

This indicates if we directly use equation (1) to estimate $\beta_{1}^{\wedge}$, we ignore the conditional mean value $\varepsilon_{1}$. Furthermore, equation (4) can be written as:

$$
\mathrm{E}\left(y_{1 i} \mid \chi_{1 i}, y_{2 i}^{*} \geq 0\right)=\chi_{1 i} \beta_{1}+\rho \sigma_{1} \lambda_{i} .
$$

Then, we get,

$$
y_{1 i}=\chi_{1 i} \beta_{1}+\rho \sigma_{1} \lambda_{i}+\mu_{i}
$$

where $\rho$ is the correlation coefficient of $\varepsilon_{1}, \varepsilon_{2} ; \sigma_{1}$ is the standard deviation of $\varepsilon_{1 i}$, and $\sigma_{2}$ is the standard deviation of $\varepsilon_{2 i}$.

Firstly, using Probit model to estimate equation (2) based on all samples, the tendency of all samples to choose quantified self-behavior was obtained. Using the estimated results, we can calculate $\lambda_{i}$.

Secondly, regard $\rho \sigma_{1}$ as a parameter to be estimated using the sample of choosing quantified self and estimate equation (6) to get $\beta_{1}^{\wedge}$. 
3.3.2. PLS Path Modeling. PLS path model mainly includes two parts: measurement model is called external model, which describes the relationship between latent variables and measurable variables. Structural model, also known as internal model, describes the relationship between endogenous latent variables and exogenous latent variables, as well as the relationship between exogenous latent variables. This study mainly uses PLS modeling to analyze the role of social networks in quantified self influencing on residents' health food consumption.

Let $\xi$ be a latent variable and $X_{h}$ be a measurable variable, then, the relationship between $\xi$ and $X_{h}$ can be expressed in three forms: reflection type, constitutive type, and polygenetic type.

(1) Reflection Type. In reflection type, latent variable (LV) reflects every measurable variable (MV), and every measurable variable can be expressed as a simple regression equation about its latent variable:

$$
X_{h}=\pi_{h_{0}}+\pi_{h} \xi+\varepsilon_{h} .
$$

The mean value $\xi$ is 0 , and the standard deviation is 1 , which satisfies the forecast specification conditions:

$$
\mathrm{E}\left(\frac{X_{h}}{\xi}\right)=\pi_{h_{0}}+\pi_{h} \xi
$$

When the reflection type appears in the model, the first step is to test the unique dimension using principal component analysis, Cronbach's $\alpha$ coefficient, and Dillon Goldstein's $\rho$ coefficient.

Principal component analysis shows that if the first eigenvalue root is greater than 1 , the second eigenvalue root is less than 1, or the second eigenvalue root is less than the first eigenvalue root, then the group of measurable variables is unique [30]. Therefore, it can be determined that the first principal component positively correlated with all or at least most of the measurable variables. If there is a negatively correlated measurable variable, it can be considered that the variable cannot fully reveal its potential variables and should be removed from the model summary.

The premise of Cronbach's coefficient as the test standard of the only dimension is that a group of $p$-dimensional measurable variables positively correlated with each other. Firstly, the group of variables should be standardized. Write the variance as follows:

$$
\operatorname{Var}\left(\sum_{h=1}^{p} X_{h}\right)=p+\sum_{h \neq h^{\prime}} \operatorname{cor}\left(X_{h}, X_{h}^{\prime}\right),
$$

where the larger the $\sum_{h \neq h^{\prime}} \operatorname{cor}\left(X_{h}, X_{h}^{\prime}\right)$, the more the measurable variables meet the requirement of unique dimension, thus introducing $\alpha^{\prime}$,

$$
\alpha^{\prime}=\frac{\sum_{h \neq h^{\prime}} \operatorname{cor}\left(X_{h}, X_{h}^{\prime}\right)}{p+\sum_{h \neq h^{\prime}} \operatorname{cor}\left(X_{h}, X_{h}^{\prime}\right)} .
$$

It is found that Cronbach's coefficient reaches the maximum value $(P-1) / P$ when $\operatorname{cor}\left(X_{h}, X_{h}^{\prime}\right)=1$

$$
\alpha=\frac{\sum_{h \neq h^{\prime}} \operatorname{cor}\left(X_{h}, X_{h}^{\prime}\right)}{p+\sum_{h \neq h^{\prime}} \operatorname{cor}\left(X_{h}, X_{h}^{\prime}\right)} \times \frac{p}{p-1} .
$$

The equation (11) can be transformed as

$$
\alpha=\frac{\sum_{h \neq h^{\prime}} \operatorname{cor}\left(X_{h}, X_{h}^{\prime}\right)}{\operatorname{Var}\left(\sum_{h=1}^{p} X_{h}\right)} \times \frac{p}{p-1} .
$$

If Cronbach's is greater than 0.7 , it indicates that the more the ratio of autocorrelation coefficient to variance approaches its maximum, the group of measurable variables meet the unique dimension.

Dillon Goldstein's $\rho$ coefficient is slightly better than Cronbach's coefficient in the evaluation of uniqueness. The coefficient is mainly set based on the simple regression model between latent variables and measurable variables. Firstly, the variance $\sum_{h=1}^{p} X_{h}$ is calculated according to equation (7) and the residual $\varepsilon_{h}$ is assumed to be independent.

$$
\operatorname{Var}\left(\sum_{h=1}^{p} X_{h}\right)=\operatorname{Var}\left(\sum_{h=1}^{p}\left(\pi_{h_{0}}+\pi_{h} \xi+\varepsilon_{h}\right)\right)=\left(\sum_{h=1}^{p} \pi_{h}\right)^{2} \operatorname{Var}(\xi)+\sum_{h=1}^{p} \operatorname{Var}\left(\varepsilon_{h}\right)
$$

The larger of $\left(\sum_{h=1}^{p} \pi_{h}\right)^{2}$, the more the group of variables meet the requirement of unique dimension, which defined $\rho$ as follows:

$$
\rho=\frac{\left(\sum_{h=1}^{p} \pi_{h}\right)^{2} \operatorname{Var}(\xi)}{\left(\sum_{h=1}^{p} \pi_{h}\right)^{2} \operatorname{Var}(\xi)+\sum_{h=1}^{p} \operatorname{Var}\left(\varepsilon_{h}\right)}
$$

Assuming that both the measurable variable $X_{h}$ and the latent variable $\xi$ are standardized, the latent variable $\xi$ can be estimated by the first principal component $t_{1}$ of the measurable variable, and $\pi_{h}$ can be estimated by the similarity coefficient $\operatorname{cor}\left(X_{h}, t_{1}\right)$ and the first principal component $t_{1}$.
$\operatorname{Var}\left(\varepsilon_{h}\right)$ can be estimated by $1-\operatorname{cor}^{2}\left(X_{h}, t_{1}\right)$. Therefore, the estimate of Dillon-Goldenstein's $\rho$ is given as

$$
\widehat{\rho}=\frac{\left(\sum_{h=1}^{p} \operatorname{cor}\left(X_{h}, t_{1}\right)\right)^{2}}{\left(\sum_{h=1}^{p} \operatorname{cor}\left(X_{h}, t_{1}\right)\right)^{2}+\sum_{h=1}^{p}\left(1-\operatorname{cor}^{2}\left(X_{h}, t_{1}\right)\right)} .
$$

If $\hat{\rho}$ is greater than 0.7 , The group of measurable variables is considered to be unique.

(2) Constructive Type. In the constructive form, the latent variable $\xi$ is generated by a group of measurable variables, which can be expressed as the sum of the weighted residuals: 


$$
\xi=\sum_{h} \bar{w}_{h} X_{h}+\delta .
$$

In constructive form, measurable variables can belong to multiple latent variables. At the same time, it meets the prediction criteria:

$$
E\left(\frac{\xi}{X_{1}, \ldots, X_{p j}}\right)=\sum_{h} \bar{w}_{h} X_{h}
$$

Suppose that the mean value of the residual vector is 0 , and it is not related to the measurable variable $X_{h}$. In the PLS algorithm parameter estimation, if the symbol is related, the variable should be deleted.

\section{Results and Discussion}

\subsection{Results}

\subsubsection{The Impact of Quantified Self on Consumers' Healthy Food Consumption}

(1) Experimental Results. Firstly, it analyzes whether different consumers engaged in quantified self-behavior. From the experimental subjects, consumers' quantified self-awareness and actual quantified self-behavior are different in different gender and age groups. From the perspective of gender (Figure 3), male's overall quantitative awareness is low, only $30 \%$ of all male subjects have high quantitative awareness while $48 \%$ of female subjects have high quantitative awareness. In the actual quantified self-behavior, $68.75 \%$ of the male subjects took the quantitative behavior in the process of choosing food, and $85.71 \%$ of the female subjects took the actual quantitative behavior. Therefore, from the perspective of gender, female subjects have higher quantitative awareness and behavior than male subjects.

From the perspective of age (Figure 4), the older the subjects are, the stronger their quantitative awareness is; $69.44 \%$ of the subjects younger than 20 years, $67.65 \%$ of the subjects between 21 and 23 years, and $75 \%$ of the subjects older than 24 years have medium or high quantitative awareness. But the results of quantified self-behavior show different trends: in the group of 21-23-year-old subjects, $90 \%$ adopted quantified self-behavior, whereas in the 20year-old and 24-year-old subjects, about 70\% chose quantified self-behavior. It can be seen that age has no significant difference in the choice of quantified self-behavior. Combined with the quantitative consciousness and quantitative behavior of the subjects, it can be seen that more than $65 \%$ of the subjects will choose quantified self-behavior.

In addition, by observing the relationship between healthy food awareness and quantified self-behavior (Figure 5(a)), we can find that the subjects with healthy food awareness are more likely to choose quantified self. Only $70 \%$ of the subjects with low healthy food awareness chose quantified self, while $75 \%$ and $87.5 \%$ of the subjects with moderate or high health food awareness chose quantified self, respectively. With the improvement of healthy food awareness, the probability of consumers choosing to quantify increases, and Hypothesis 1 is verified.
The results of independent sample $T$ test shows that there is no significant difference in consumption willingness of healthy food between CQG and PQG (Figure 5(b)). Compared with CQG, subjects of PQG report slightly higher willingness to consume healthy food $(M=1.83, \mathrm{SD}=0.83$ vs $M=2.1, \mathrm{SD}=0.80, F(1,58)=1.59, p=0.2121)$. However, there are significant differences in healthy food consumption intention between COQ and AQG, as well as PGQ and AQG. Compared with CQG, AQG has higher healthy food consumption intention $(M=2.47, \mathrm{SD}=0.62$ vs $M=1.83$, $\mathrm{SD}=0.83, F(1,58)=11.03, p=0.0016)$, indicating that the subjects who have the initiative to take quantified self-behavior have higher healthy food consumption intention. AQG has higher health food consumption intention than PQG $(M=2.47, \mathrm{SD}=0.62$ vs $M=2.1, \mathrm{SD}=0.80, F(1,58)=$ 3.87, $p=0.0537)$, which indicates that the subjects with active quantified self-behavior have higher healthy food consumption intention than those with passive quantified self.

As for the influence of quantified self on the consumption scale of healthy food, the result of independent sample $T$ test shows that there is no significant difference between CQG and PQG (Figure 5(c)). Compared with CQG, PQG report slightly higher consumption scale of health food $(M=23.43, \mathrm{SD}=3.97$ vs $M=21.78, \mathrm{SD}=5.65, F(1,58)=$ $1.70, p=0.1968)$. However, there are significant differences in the scale of healthy food consumption between COQ and AQG, as well as PQG and AQG. The subjects of AQG have higher scale of healthy food consumption than CQG $(M=27.52, \mathrm{SD}=5.52$ vs $M=21.78, \mathrm{SD}=5.65, F(1,58)=$ 15.79, $p=0.0002)$. Compared with PQG, AQG has higher consumption scale of health food $(M=27.52, \mathrm{SD}=5.52$ vs $M=23.43, \mathrm{SD}=3.97, F(1,58)=10.82, p=0.0017)$, which indicates that the subjects with active self-quantification have higher consumption scale of health food than those with passive self-quantification.

Through the analysis of the influence of CQG, PQG, and AQG on consumers' willingness and scale of healthy food consumption, it can be found that the subjects with active quantification have higher willingness and scale of food consumption, and quantified self-behavior can promote consumers' willingness and scale of healthy food consumption. Hypotheses 2 and 3 are verified.

(2) Empirical Results. Heckman two-step method is used to test whether consumers choose quantified self-behavior and the relationship between quantitative behavior and consumers' healthy food consumption intention and scale. The results are shown in Table 2. In that, column (1) is the Probit regression of consumers' quantitative behavior, and column (2) and column (3) indicate the influence of quantified selfbehavior on consumers' willingness and scale of healthy food consumption under the control of self-selection bias.

From the results of column (1), the constant coefficient is 0.324 , which means that the ratio of quantitative to nonquantized is 0.324 without considering other influences. The ratio of consumer selection quantification to nonquantized is 1.383. It shows that in the survey sample, the individual who chooses quantification is $38.3 \%$ higher than the 


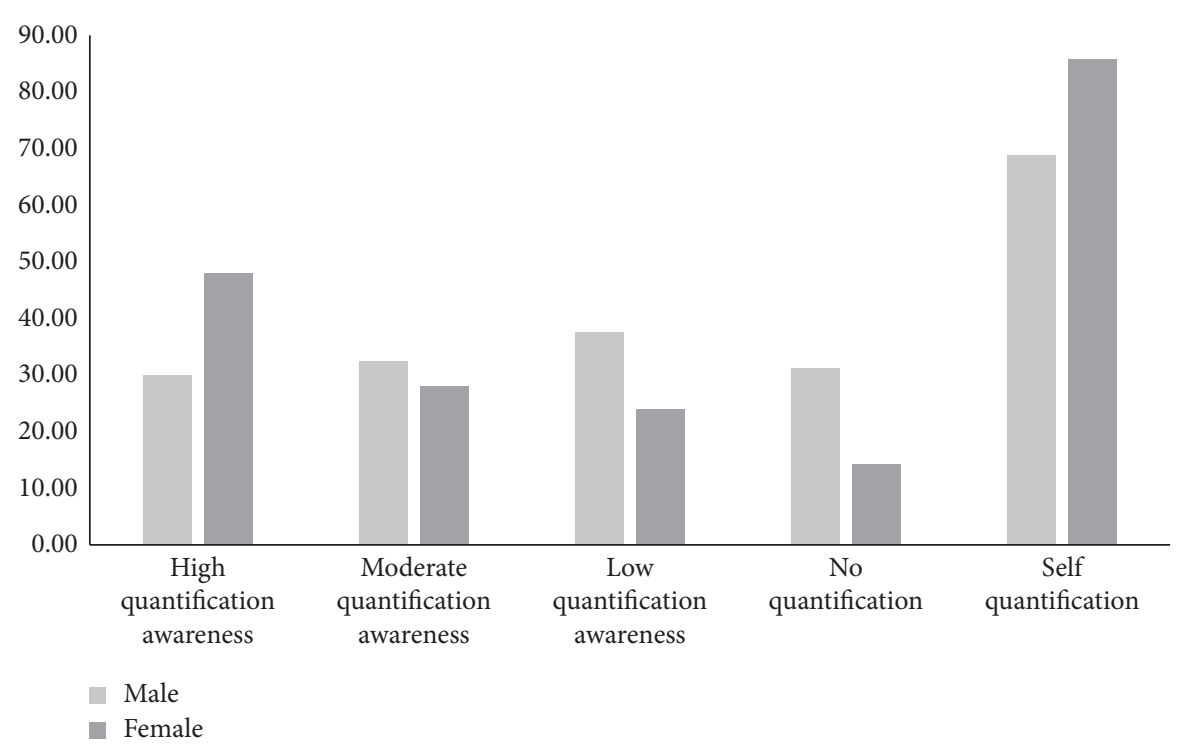

FIgURE 3: Gender differences in consumers' quantitative self-awareness and behavior.

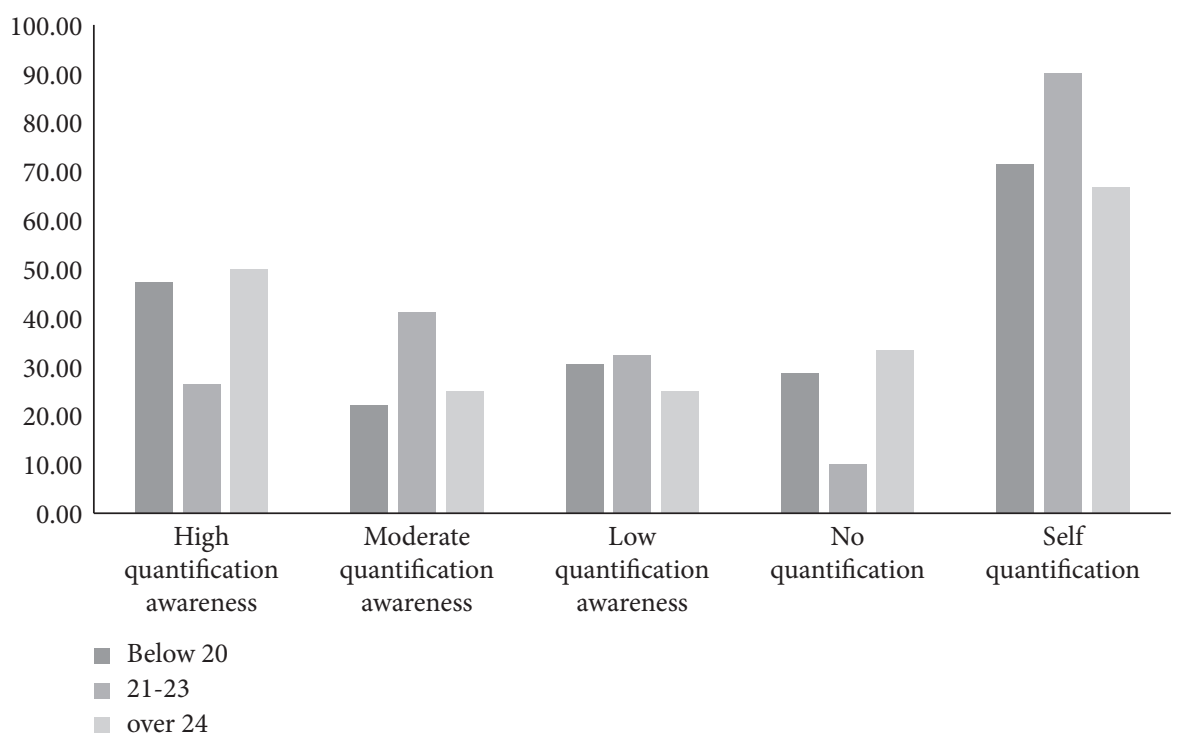

FIgURE 4: Gender differences in consumers' quantitative self-awareness and behavior.

individual who has not selected quantification. In addition, health awareness has a significant positive effect on consumers' quantified self choice. The coefficient after logarithm transformation is 1.035 , which shows that the consumers with high health awareness are 3.5\% higher than those with low health awareness. Hypothesis 1 is verified again. From the results of column (2), the consumer quantified self has a significant positive effect on the consumption willingness of healthy food, with a coefficient of 0.292 and significant at the level of $1 \%$. It shows that under the condition, the consumer's quantified self-behavior is improved, and the consumers' willingness to consume healthy food products is increased by $29.2 \%$, Hypothesis 2 is verified. The results of column (3) show that the influence of consumer quantified self on consumption scale of healthy food is 0.351 , which shows that with the improvement in consumers' quantified self-behavior, the consumption scale of healthy food of consumers increases by $35.1 \%$, and Hypothesis 3 is verified.

4.1.2. The Moderating Role of Social Networks. Furthermore, PLS path modeling is used to test the moderating role of social networks in the process of quantified self impact on healthy food consumption. The results are shown in Table 3. In that, columns (1)-(3) are the moderating results of social networks in the process of quantified self-influence on consumers' healthy food consumption intention, and columns (4)-(6) are the moderating results of social networks in the process of quantified self-influence on consumers' healthy food consumption scale.

From the results of column (1), the quantified self-behavior and social networks have positive and significant effects on 


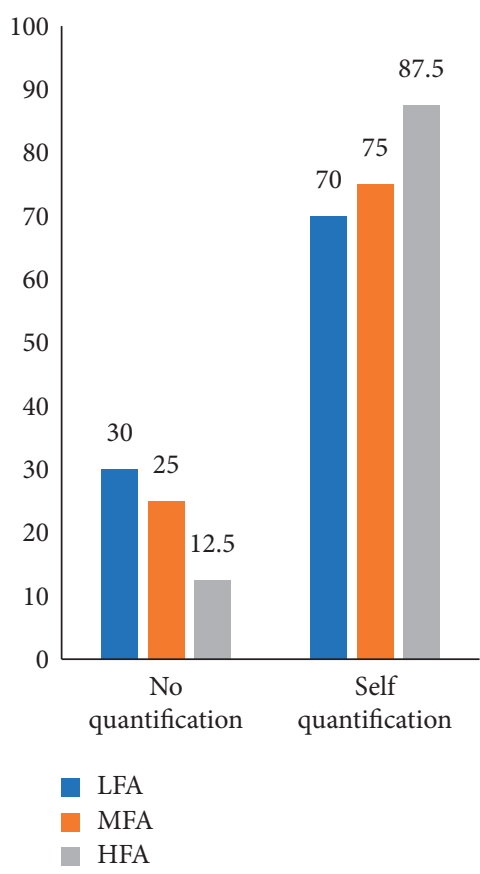

(a)

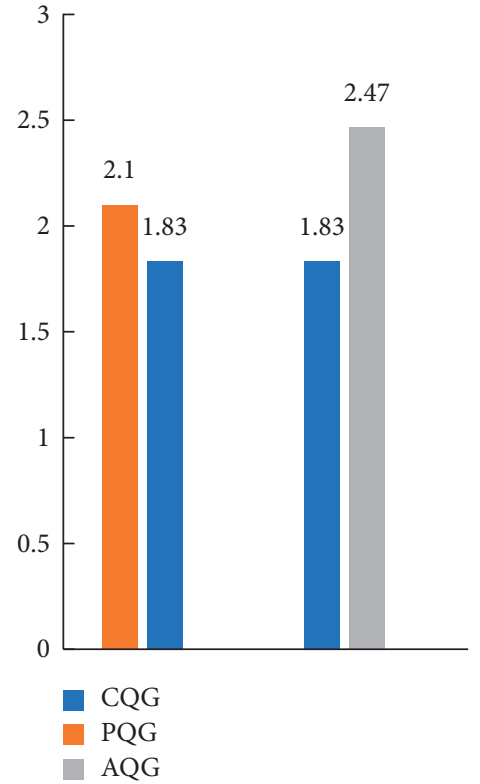

(b)

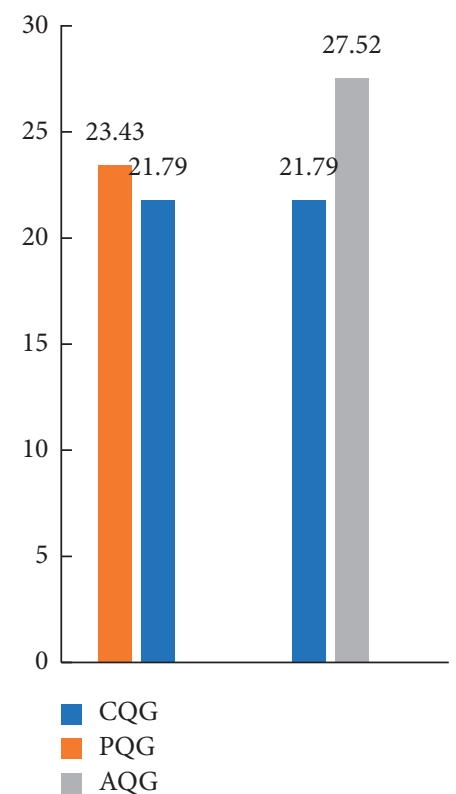

(c)

FIGURE 5: The effect of quantified self on consumers' willingness and scale of healthy food consumption. (a) Quantitative behavior choice. (b) Consumption awareness. (c) Consumption scale.

TABLE 2: The influence of quantified self on consumers' willingness and scale of healthy food consumption.

\begin{tabular}{|c|c|c|c|}
\hline & $\begin{array}{c}(1) \\
\text { Quantified self } \\
\end{array}$ & $\begin{array}{c}(3) \\
\text { Consumption intention } \\
\end{array}$ & $\begin{array}{c}(4) \\
\text { Consumption scale }\end{array}$ \\
\hline Constant & $\begin{array}{c}0.324^{* * *} \\
(0.031)\end{array}$ & $\begin{array}{c}-0.963^{* * *} \\
(0.224)\end{array}$ & $\begin{array}{c}-0.383 \\
(0.228)\end{array}$ \\
\hline Quantified self & & $\begin{array}{c}0.292^{* * *} \\
(0.032)\end{array}$ & $\begin{array}{c}0.351^{* * *} \\
(0.033)\end{array}$ \\
\hline Register & $\begin{array}{c}0.118 \\
(0.104)\end{array}$ & $\begin{array}{l}0.153^{*} \\
(0.068)\end{array}$ & $\begin{array}{l}0.212^{* *} \\
(0.070)\end{array}$ \\
\hline Gender & $\begin{array}{l}-0.030 \\
(0.089)\end{array}$ & $\begin{array}{c}0.023 \\
(0.059)\end{array}$ & $\begin{array}{c}0.004 \\
(0.060)\end{array}$ \\
\hline Age & $\begin{array}{c}0.051^{* * *} \\
(0.006)\end{array}$ & $\begin{array}{c}0.030^{* * *} \\
(0.004)\end{array}$ & $\begin{array}{c}0.004 \\
(0.004)\end{array}$ \\
\hline Education & $\begin{array}{c}0.102 \\
(0.094)\end{array}$ & $\begin{array}{l}0.132^{*} \\
(0.062)\end{array}$ & $\begin{array}{l}0.137^{*} \\
(0.063)\end{array}$ \\
\hline Income & $\begin{array}{l}0.122^{* *} \\
(0.046)\end{array}$ & $\begin{array}{c}0.002 \\
(0.031)\end{array}$ & $\begin{array}{c}0.052 \\
(0.031)\end{array}$ \\
\hline Health knowledge & $\begin{array}{c}0.045 \\
(0.056)\end{array}$ & $\begin{array}{c}0.058^{* * *} \\
(0.017)\end{array}$ & $\begin{array}{c}0.060^{* *} \\
(0.028)\end{array}$ \\
\hline Health awareness & $\begin{array}{c}0.034^{* * *} \\
(0.011)\end{array}$ & $\begin{array}{c}0.015 \\
(0.040)\end{array}$ & $\begin{array}{c}0.046^{* * *} \\
(0.010)\end{array}$ \\
\hline $\begin{array}{l}N \\
\text { Adj. } R^{2}\end{array}$ & 942 & $\begin{array}{c}942 \\
0.233\end{array}$ & $\begin{array}{c}942 \\
0.206\end{array}$ \\
\hline
\end{tabular}

Standard errors in parentheses, ${ }^{*} p<0.05,{ }^{* *} p<0.01,{ }^{* * *} p<0.001$.

consumers' willingness to purchase healthy food with coefficients of 0.190 and 0.273 , respectively, and both are significantly at the level of $1 \%$. At the same time, the intersection of quantified self and social networks has a positive impact on the consumption intention, which means that social networks will moderate the impact of quantified self-behavior on the consumption willingness. That is, the more complex the social networks are, the stronger the impact of quantified self-behavior on consumers' consumption of healthy food is. Column (4) is the moderating effect of social networks on the 
TABLE 3: The moderating role of social networks.

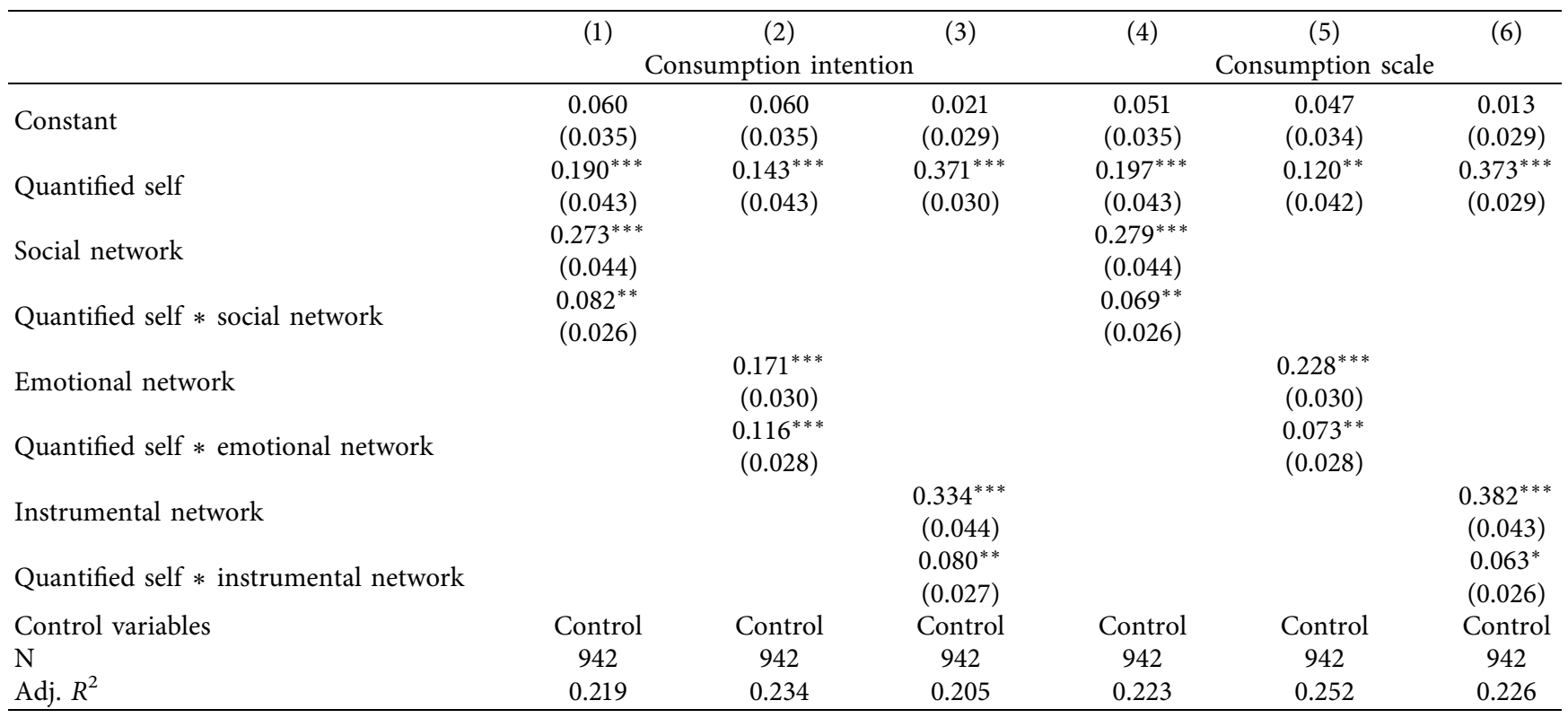

Standard errors in parentheses, ${ }^{*} P<0.05,{ }^{* *} P<0.01,{ }^{* * *} P<0.001$.

consumption scale of healthy food, and its moderating coefficient is 0.069 . Hypothesis 4 is verified.

Columns (2) and (5) show the moderating effects of emotional social networks on the relationship between quantified self and healthy food consumption. The results show that whether it is consumers' willingness to consume healthy food or consumption scale, emotional social networks have positive moderating effects with coefficients of 0.116 and 0.073 respectively. The results of column (3) and (6) show that the instrumental networks also have positive moderating effects with coefficients of 0.080 and 0.063 , and the coefficients are significantly at the level of $5 \%$ and $10 \%$. The results of emotional networks and instrumental networks further verify Hypothesis 4 . At the same time, from the coefficients, whether it is healthy food consumption intention or consumption scale, the cross-term coefficient of quantified self and emotional networks is greater than that of quantified self and instrumental networks, indicating that the moderating effect of emotional networks is stronger, and Hypothesis 5 is verified.

4.2. Discussion. The results of experimental and empirical tests are consistent with the conclusion of Ortega et al. [31] and Pocol et al. [32] but has differences. The results of Ortega et al. [31] showed that the consumers' selection of food safety was affected by consumer preferences; they measured consumer preferences for select food safety attributes in pork and took food safety risk perceptions into account. Several choice experiment models, including latent class and random parameters logit, were constructed to capture heterogeneity in consumer preferences. Their results suggest that Chinese consumers have the highest willingness to pay for a government certification program, followed by third- party certification, a traceability system, and a productspecific information. But our results show that consumers' willingness and scale of healthy food consumption could be also affected by quantified self-behavior. Pocol et al. [32] explored Generation Z university students' clusters based on the consumption of daily fruits and vegetables in an emerging market economy and found most cluster members are aware of the value of regular fresh fruit and vegetable consumption in order to maintain health and overall wellbeing [33]. Our results complement the conclusion that customers with quantified self-behavior will have higher willingness to buy safety food.

The results of moderating role of social networks show the similar situation of Kim and Lee [34]. They pointed out that the more friends in Facebook, the more likely individuals chose self-presentation, then individuals would make similar decisions. Hu et al. [35] used Bayesian personalized ranking based on multiple-layer neighborhoods and pointed out that social networks would affect individuals' behavior. Though Marcel et al. [36] stated that the information sources of consumers' selection of food safety was relatives and friends, our results shows that emotional social network plays a stronger role in quantifying self-influence on healthy food consumption behavior.

In the context of big data, the digital divide encourages opportunistic enterprises to exploit the rights and interests of consumers, and the emergence of quantitative self indicates the beginning of comprehensive digitization in the field of consumer cognition. Through the tracking and measurement of self-behavior state, consumers' health status and life process are becoming more and more visual and predictable. The implementation and penetration of quantitative self makes consumers' demand judgment and behavior choice more and more accurate and rational. This is very 
important for consumers to pay attention to healthy food consumption or nutrition.

Based on the theory of information perception and the risk perception theory, combined with social cognition, this study explores the internal mechanism of self quantify on healthy food consumption, which brings new insights for analyzing quantitative behavior and understanding the formation of consumers' healthy food consumption participation intention. In terms of research perspective, due to the limitation of perspective, relevant studies lack holistic thinking on the internal mechanism of the formation of consumers' willingness to buy healthy food. Breaking through the limitations of existing studies focusing on the individual level to explore relevant issues, combined with the reality of the increasing socialization of quantitative self under the support of technology, this study more accurately explains the connotation of quantitative self-concept from the perspective of the combination of individual and community, and comprehensively understands the formation mechanism of consumers' willingness to quantitative self in healthy food consumption. In terms of research content, most of the existing studies regard constraints such as limited time and energy, insufficient operating skills, and unhealthy habits as the main reasons for consumers' quantifying themselves in healthy food consumption and do not consider the impact of social networks. From the perspective of individual differences, this study constructs a theoretical framework for analyzing consumers' healthy food consumption based on information perception and the risk perception theory, which makes a reasonable supplement to the research on the consumers' quantitative selfbehavior and healthy food consumption behavior. Focusing on the essence of quantitative self as a socialized practice and relying on social cognitive theory, this article explains the differentiated choice of consumers on whether to participate in quantitative self in the face of social networks. From the perspective of relationship, the internal mechanism of different social networks on consumers' healthy food consumption is introduced to further clarify the applicable boundary of the theory. In terms of research methods, although the existing studies recognize the necessity of participation in the realization of quantitative self positive utility and emphasize the importance of clarifying the internal mechanism of consumers' quantitative self participation behavior on healthy food consumption, the understanding of relevant issues is still in the stage of descriptive exploration. Based on the literature review, this study forms relevant hypotheses, which are verified by a series of experiments and questionnaires, and defines and confirms the internal relationship of various elements in the relationship of consumers' quantitative self and healthy food consumption.

\section{Conclusions}

This study analyzed consumers' quantified self-behavior and healthy food consumption through laboratory experiments and field investigation and explored the role of social networks in quantified self-behavior and healthy food consumption from the perspective of complex network. Through theoretical analysis and empirical research, this study obtains three main results: (1) Health awareness can promote consumers to choose quantified self-behavior; (2) consumers' quantified self-behavior is helpful to promote their purchase intention and purchase scale of healthy food; (3) social networks play a positive moderating role in the relationship of quantified selfbehavior and healthy food consumption. Both emotional networks and instrumental networks have significant moderating effects, but the former is stronger.

This article discusses the impact of quantitative self on consumers' healthy food consumption from the perspective of social network and deeply explores how different social networks affect the relationship between the two. Also, this article expands the theory of information perception and the risk perception theory, and it strengthens the role of information cognition, information transmission, and risk cognition in the connection of different social networks, which will deeply affect the impact of quantifying self on food consumption. In addition, in terms of practical significance, the conclusions of this article can provide practical guidance for food enterprises to optimize product packaging and quantify innovative product design. In addition, the relevant conclusions can also provide some support for the government to guide residents to establish food nutrition concept, form quantitative self habits, make food consumption decisions, and buy food reasonably.

Compared with previous studies, this study has some innovations, such as using experimental data and survey data at the same time to strengthen the diversity of data sources and the reliability of empirical results. This article discusses the quantified self behavior and healthy food consumption behavior of consumers, which is helpful to expand the research of consumer behavior from the cross perspective of behavior and economics. However, there are also some shortcomings in this study. For example, although the scale of this study cites the mature scale of previous studies as reference, due to the diversity and complexity of consumers' behavior and social networks, the questionnaire items may not fully reflect the relevant variables. In addition, this study mainly focuses on the moderating role of social networks, but whether there are other roles needs to be further explored in the follow-up research.

\section{Data Availability}

The data used to support the findings of this study are available from the corresponding author upon request.

\section{Conflicts of Interest}

The authors declare that there are no conflicts of interest regarding the publication of this paper.

\section{Acknowledgments}

This study was supported by National Natural Science Foundation of China (72003113), Humanities and Social Sciences Research Fund of the Ministry of Education (18YJC890012), and Soft Science General Project of Shaanxi Innovation Capability Support Plan (2020KRM118). 


\section{References}

[1] H.-Y. Lin and M.-H. Hsu, "Using social cognitive theory to investigate green consumer behavior," Business Strategy and the Environment, vol. 24, no. 5, pp. 326-343, 2015.

[2] M. A. Mccrory, P. J. Fuss, N. P. Hays, A. G. Vinken, A. S. Greenberg, and S. B. Roberts, "Overeating in America: association between restaurant food consumption and body fatness in healthy adult men and women ages 19 to 80 ," Obesity Research, vol. 7, no. 6, 2012.

[3] L. Robertsson, "Quantified self: an overview and the development of a universal tracking application," Unpublished Doctorial Dissertation, Umea University, Västerbotten, 2014.

[4] M. Almalki, K. Gray, and F. Martin-Sanchez, "Activity theory as a theoretical framework for health self-quantifcation: a systematic review of empirical studies," Journal of Medical Internet Research, vol. 18, no. 5, pp. 131-148, 2016.

[5] B. K. Choi, H. K. Moon, and E. Y. Nae, "Cognition- and affectbased trust and feedback-seeking behavior: the roles of value, cost, and goal orientations," Journal of Psychology, vol. 148, no. 5, pp. 603-620, 2014.

[6] Y. Zhang, D. Li, and H. Jin, "Security risk perception, quantitative information preference and willingness to participate in consumption: decoding the decision logic of food consumers," Modern Finance-Journal of Tianjin University of Finance and Economics, vol. 39, no. 1, pp. 86-98, 2019.

[7] M. Ruckenstein and M. Pantzar, "Beyond the quantified self: thematic exploration of a dataistic paradigm," New Media and Society, vol. 19, no. 3, pp. 401-418, 2017.

[8] R. L. Trivers, "The evolution of reciprocal altruism," The Quarterly Review of Biology, vol. 46, no. 1, pp. 35-57, 1971.

[9] S. Quan and Y. Zeng, "Research on consumers' search behavior of food safety information-_based on the survey of consumers in Beijing," Agricultural Technology Economics, no. 4, pp. 45-54, 2013.

[10] R. An, "Effectiveness of subsidies in promoting healthy food purchases and consumption: a review of field experiments," Public Health Nutrition, vol. 16, no. 7, pp. 1215-1228, 2013.

[11] A. Booth, A. Barnes, A. Laar et al., "Policy action within urban African food systems to promote healthy food consumption: a realist synthesis in Ghana and Kenya," International Journal of Health Policy and Management, 2020.

[12] D. Li and Y. Zhang, "The effect of quantifying self and its influence mechanism on consumer participation behavior," Management Science, vol. 31, no. 3, pp. 112-124, 2018.

[13] D. C. Aryani, Impact of Microbial Variablity on Food Safety and Quality, Wageningen University, Wageningen, Netherlands, 2016.

[14] T. Zhang and J. Lu, "Research on the influence of food labeling information on consumers' purchasing decisions-— taking infant food as an example," Forum on Statistics and Information, no. 9, pp. 107-113, 2012.

[15] T. C. Schroeder, G. T. Tonsor, J. M. E. Pennings, and J. Mintert, "Consumer food safety risk perceptions and attitudes: impacts on beef consumption across countries," The B.E. Journal of Economic Analysis \& Policy, vol. 7, no. 1, p. $1848,2007$.

[16] T. Meyvis and C. Janiszewski, “Consumers' beliefs about product benefits: the effect of obviously irrelevant product information," Journal of Consumer Research, vol. 28, no. 4, pp. 618-635, 2002.

[17] E. K. Choe, N. B. Lee, and B. Lee, "Understanding quantifiedselfers' practices in collecting and exploring personal data," in Proceedings of the Sigchi Conference on Human Factors in
Computing System, pp. 1143-1152, ACM, Toronto, ON, Canada, April 2014.

[18] S. Erdelez and K. Rioux, "Sharing information encountered for others on the web," New Review of Information Behaviour Research, vol. 1, no. 1, pp. 219-233, 2000.

[19] K. Rioux, "Information acquiring-and-sharing," Theories of Information Behavior, vol. 24, no. 2, pp. 169-173, 2005.

[20] F. Xiong, X. Wang, S. Pan, H. Yang, H. Wang, and C. Zhang, "Social recommendation with evolutionary opinion dynamics," IEEE Transactions on Systems, Man, and Cybernetics: Systems, vol. 50, no. 10, pp. 3804-3816, 2020.

[21] S. Bratu, "Can social media influencers shape corporate brand reputation? Online followers' trust, value creation, and purchase intentions," Review of Contemporary Philosophy, vol. 18, pp. 157-163, 2018.

[22] J. C. Hollowell, Z. Rowland, T. Kliestik, J. Kliestikova, and V. V. Dengov, "Customer loyalty in the sharing economy platforms: how digital personal reputation and feedback systems facilitate interaction and trust between strangers," Journal of Self-Governance and Management Economics, vol. 7, no. 1, pp. 13-18, 2019.

[23] R.-A. Pop, Z. Săplăcan, D.-C. Dabija, and M.-A. Alt, "The impact of social media influencers on travel decisions: the role of trust in consumer decision journey," Current Issues in Tourism, pp. 1-21, 2021.

[24] A. Drugău-Constantin, "Is consumer cognition reducible to neurophysiological functioning?" Economics, Management, and Financial Markets, vol. 14, no. 1, pp. 9-14, 2019.

[25] C.-O. Mirică Dumitrescu, "The behavioral economics of decision making: explaining consumer choice in terms of neural events," Economics, Management, and Financial Markets, vol. 14, no. 1, pp. 16-20, 2019.

[26] J. Jin, Y. Li, X. Zhong, and L. Zhai, "Why users contribute knowledge to online communities: an empirical study of an online social Q\&A community," Information and Management, vol. 52, no. 7, pp. 840-849, 2015.

[27] F. Xiong, W. Shen, H. Chen, S. Pan, X. Wang, and Z. Yan, "Exploiting implicit influence from information propagation for social recommendation," IEEE Transactions on Cybernetics, vol. 50, no. 10, pp. 4186-4199, 2020.

[28] Y. Zhou, L. Huo, and X. Peng, "Food safety: consumer attitudes, purchasing intentions, and the influence of information-a survey and analysis of supermarket consumers in Nanjing," Journal of Consumer Research, vol. 42, p. 6, 2016.

[29] Z. W. Fang, "The relationship between Internet addiction, coping, loneliness and online social support: a comparison between male and female college students," Journal of Educational Psychology, vol. 41, no. 4, pp. 773-797, 2010.

[30] J. M. E. Pennings and B. Wansink, "Channel contract behavior: the role of risk attitudes, risk perceptions, and channel members' market structures," Journal of Business, vol. 77, no. 4, pp. 697-724, 2004.

[31] D. L. Ortega, H. H. Wang, L. Wu, and N. J. Olynk, "Modeling heterogeneity in consumer preferences for select food safety attributes in China," Food Policy, vol. 36, no. 2, pp. 318-324, 2011.

[32] C. B. Pocol, V. Marinescu, D.-C. Dabija, and A. Amuza, "Clustering Generation Z university students based on daily fruit and vegetable consumption: empirical research in an emerging market," British Food Journal, vol. 123, no. 8, pp. 2705-2727, 2021.

[33] J. Blom-Hoffman, C. Kelleher, T. J. Power, and S. S. Leff, "Promoting healthy food consumption among young 
children: evaluation of a multi-component nutrition education program," Journal of School Psychology, vol. 42, no. 1, pp. 45-60, 2004.

[34] J. Kim and J.-E. R. Lee, "The Facebook paths to happiness: effects of the number of Facebook friends and self-presentation on subjective well-being," Cyberpsychology, Behavior, and Social Networking, vol. 14, no. 6, pp. 359-364, 2011.

[35] Y. Hu, F. Xiong, S. Pan, X. Xiong, L. Wang, and H. Chen, "Bayesian personalized ranking based on multiple-layer neighborhoods," Information Sciences, vol. 542, pp. 156-176, 2021.

[36] M. Kornelis, J. de Jonge, L. Frewer, and H. Dagevos, "Consumer selection of food-safety information sources," Risk Analysis, vol. 27, no. 2, pp. 327-335, 2007. 